\title{
A Hollow Complete Denture for Severely Resorbed Mandibular Ridges: An Innovative and Simplified Technique
}

\author{
Ruksana Farooqui ${ }^{1}$, Meena A Aras $^{2}$, Vidya Chitre $^{3}$
}

\begin{abstract}
Prosthetic rehabilitation of severely atrophic mandibular ridges poses a challenging clinical situation. The reduction in the basal seat area contributes to reduced retention and stability. Extreme ridge resorption increases the interridge distance, which results in increased height and weight of the prosthesis, thus further compromising its retention and stability and increasing the rate of residual ridge resorption. This can be overcome by making the prosthesis lightweight. This article describes an effective technique of fabricating a hollow mandibular complete denture, thereby reducing the weight of the prosthesis.

Keywords: Denture retention, Light-weight prosthesis, Residual ridge resorption.

International Journal of Prosthodontics and Restorative Dentistry (2019): 10.5005/jp-journals-10019-1242
\end{abstract}

\section{BACKGROUND}

Prosthodontic rehabilitation of resorbed alveolar ridges is clinically challenging. Severe resorption of either ridge will lead to a reduced denture-bearing area, which in turn will affect the retention, stability, and support for the complete denture. Extreme ridge resorption also results in increased interarch space. ${ }^{1}$ Restoration of the lost vertical dimension often results in increased weight of complete dentures, which further compromises the retention and stability of the prosthesis. This also overloads the underlying hard and soft tissues exacerbating the ridge resorption.

In the past, several authors advocated "weighted" dentures for severely resorbed mandibular ridges, as they contribute to the retention and stability of the prosthesis, aided by gravitational forces. ${ }^{2,3}$ However, studies have shown that stability of dentures can be enhanced by improving the fit of the denture base without increasing the weight of the dentures. ${ }^{4,5}$ A study conducted by Ohkubo and $\mathrm{Hosoi}^{6}$ showed that the weight of the denture has no effect on its retention and stability. Some criticism also arose that increased weight of the dentures may cause accelerated residual ridge resorption. ${ }^{7,8}$

Fabrication of the hollow denture has been tried using various methods to reduce the weight of the prosthesis. This case report describes a novel technique for fabrication of a hollow mandibular denture for a patient with severe ridge resorption.

\section{Case Description}

A 68-year-old female patient reported to Department of Prosthodontics, Goa Dental College and Hospital, Bambolim, Goa, India, with the chief complaint of difficulty in eating and speaking due to loss of teeth. History revealed that she had lost her teeth due to periodontal involvement and had been edentulous for 9 years. A thorough clinical and radiographic examination was performed. Clinical examination revealed that maxillary and mandibular ridges were atrophic. Medical history revealed no underlying systemic disorder. Various treatment options discussed were implant-supported prosthesis and conventional complete dentures. Pros and cons of all were explained to the patient.
${ }^{1-3}$ Department of Prosthodontics, Goa Dental College and Hospital, Bambolim, Goa, India

Corresponding Author: Ruksana Farooqui, Department of Prosthodontics, Goa Dental College and Hospital, Bambolim, Goa, India ,Phone: +91 7218282688, e-mail: farooquiruksana@gmail.com

How to cite this article: Farooqui R, Aras MA, Chitre V. A Hollow Complete Denture for Severely Resorbed Mandibular Ridges: An Innovative and Simplified Technique. Int J Prosthodont Restor Dent 2019;9(4):124-127.

Source of support: Nil

Conflict of interest: None

She decided in favor of conventional complete denture due to the cost involved and the surgical procedure involved in an implantsupported prosthesis.

Conventional clinical and laboratory procedures were carried out up till the try-in stage with the exception of using the admix technique at the definitive impression stage and the mandibular record base was fabricated with the heat-cured acrylic resin. A neutral zone impression technique was applied at the maxillomandibular relations stage.

\section{Laboratory Procedure}

- Notches were made at five sites on the land area of the mandibular cast and the waxed mandibular denture was sealed to the master cast. The mandibular trial denture was duplicated with the irreversible hydrocolloid impression material (Tropicalgin, Zhermack, Badia Polesine, Italy) and poured in the type III dental stone (Kalstone, Kalabhai Pvt., Ltd., Mumbai, Maharashtra, India) to obtain a working cast.

- An 1-mm-thick BIOPLAST (Scheu Dental GmbH, Iserlohn, Germany) sheet was pressed on the working cast to obtain a template (Fig. 1).

- The mandibular trial denture was invested and dewaxed in the conventional manner.

- With the permanent denture base in place, the clear template was placed on the master cast utilizing the indices on the land 


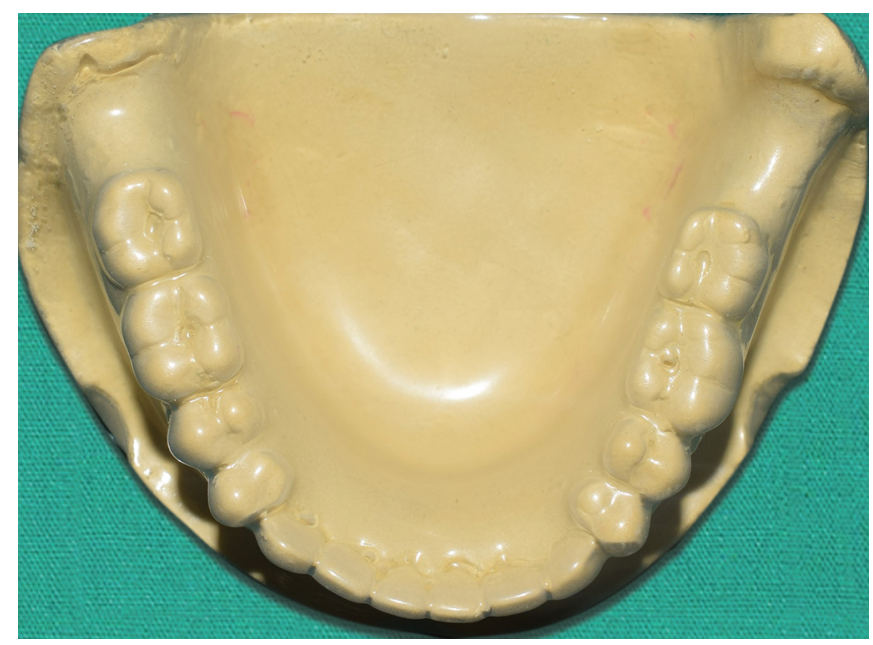

Fig. 1: A 1-mm-thick polyethylene sheet pressed on a duplicate stone cast of the waxed mandibular complete denture

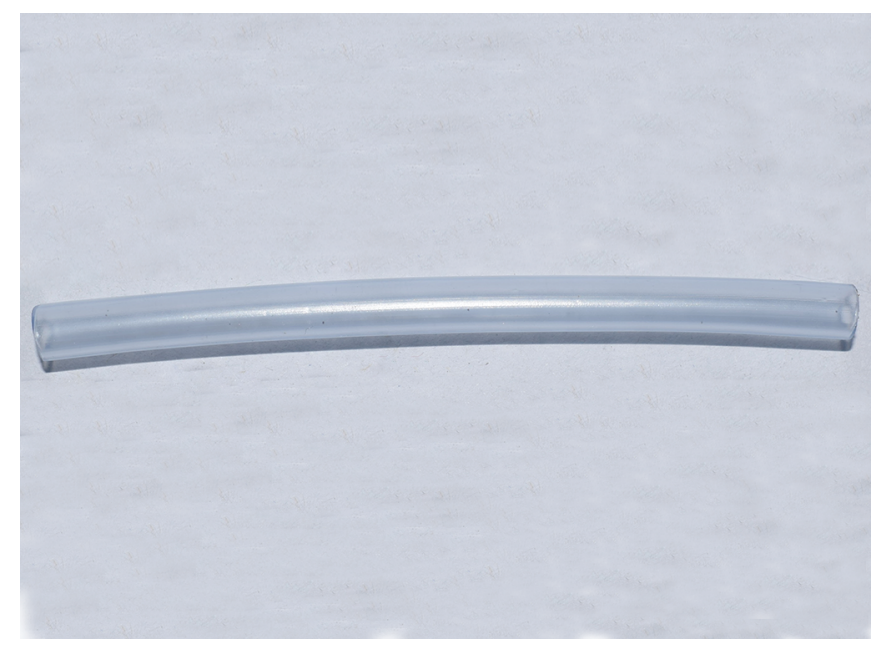

Fig. 3: Clear food grade PVC tube

area of the cast. A line was drawn on the template $2 \mathrm{~mm}$ below the cervical end of the teeth.

- By piercing through the template using an endodontic file with a rubber stop, the space between the line drawn and the permanent denture base was checked to determine the area available for the spacer. Based on the value for the spacer, a flexible food grade Poly vinyl chloride (PVC) tube (IWS Healthcare services, Malaysia) with a diameter of $5 / 16$ inches was selected (Fig. 2). Length of the PVC tube was determined based on the arch length. The ends of the PVC tube were sealed with the autopolymerizing acrylic resin. The PVC tube was bent to the arch form and fixed onto the permanent denture base with cyanoacrylate adhesive (Fig. 3).

- The clear template was then placed over the master cast to verify $2-3 \mathrm{~mm}$ of space all around between the PVC tube and the template (Fig. 4).

- The other half of the flask was seated to verify the complete closure of the flask. The heat-cured acrylic resin was mixed, packed, and processed in the conventional manner (Fig. 5).

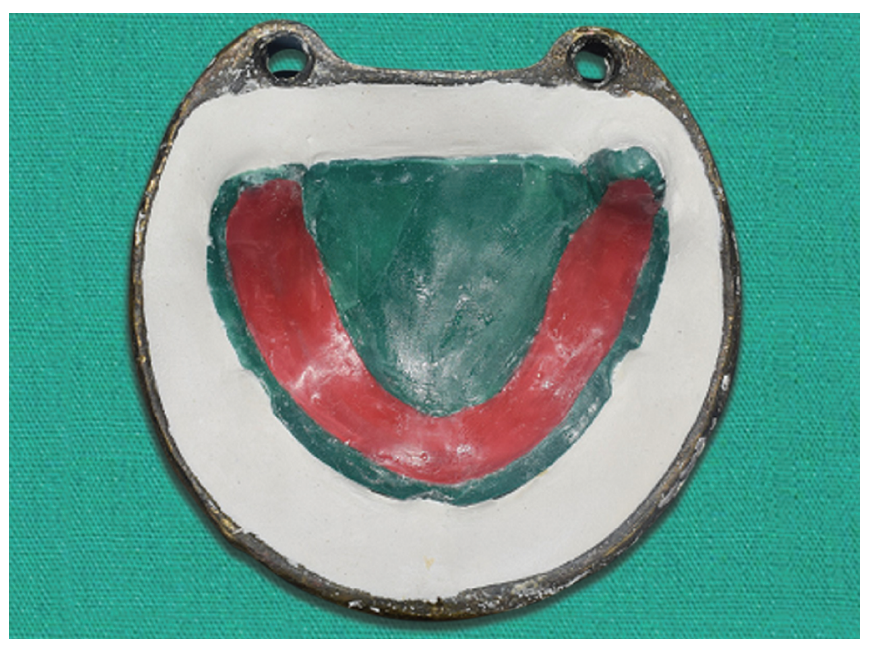

Fig. 2: The 2-mm-thick modeling wax adapted over the master cast to ensure adequate and uniform resin thickness in the complete denture

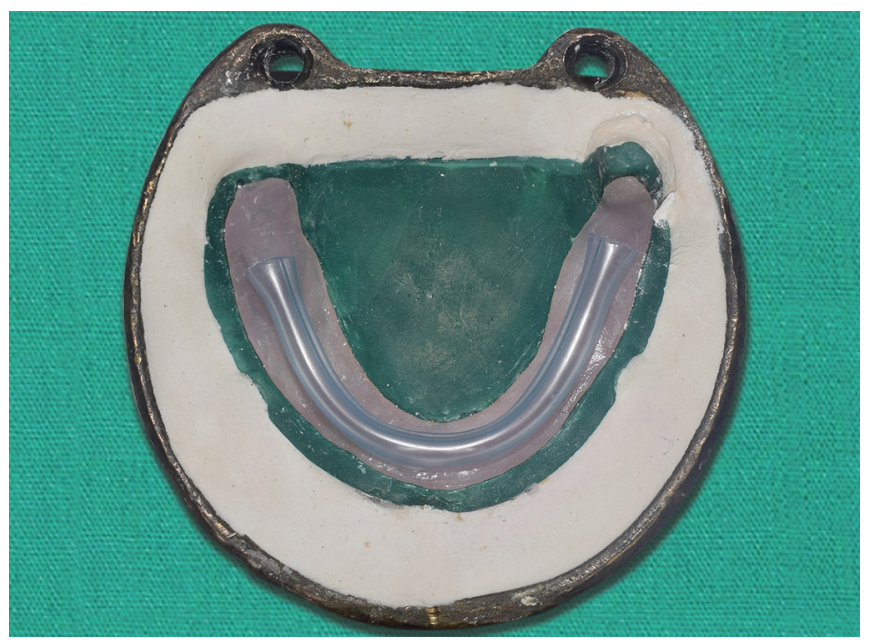

Fig. 4: Clear food grade PVC tube placed over the master cast with 2-mm-thick modeling wax adapted to it

- The denture was retrieved, finished, and polished in the usual manner (Fig. 6). A water test was performed to evaluate the hollow test as evident by the floating denture.

- Upper and lower dentures were delivered to the patient. The patient was reviewed after a week, and minor adjustments were made.

- The finished mandibular denture was duplicated into a solid prosthesis to compare the difference in weight if it had not been hollowed and this difference was found to be $5 \mathrm{~g}$ (Fig. 7).

\section{Discussion}

Loss of teeth leads to residual ridge resorption that is a complex biophysical process affected by various anatomic, prosthetic, functional, and metabolic factors. ${ }^{9}$ Increased interarch distance in patients with excessive ridge resorption results in heavy prosthesis that has detrimental effects on the underlying tissues. Making the prosthesis hollow not only helps in reducing the weight of 


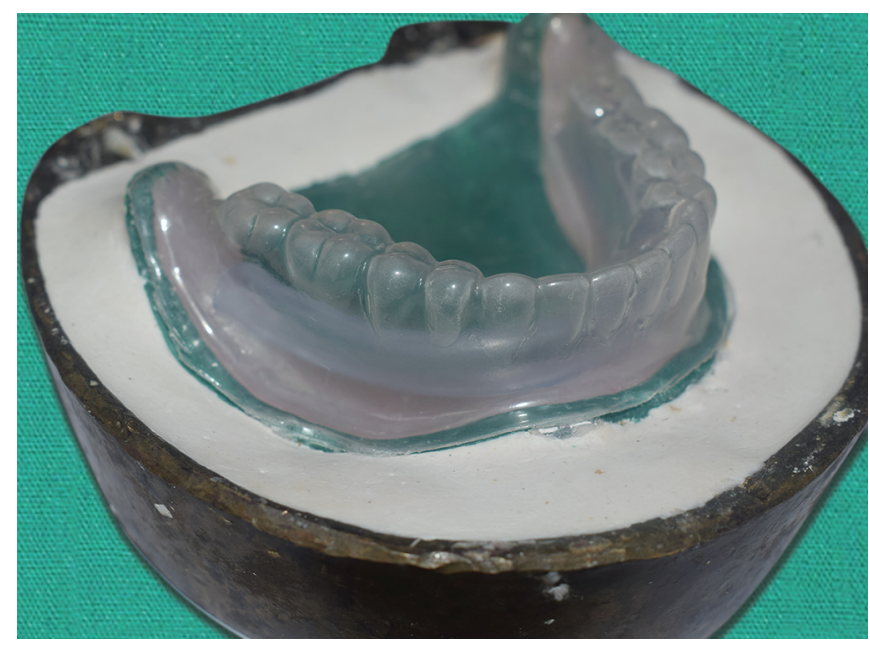

Fig. 5: A 2-mm space left between a food grade PVC tube and the BIOSTAR template

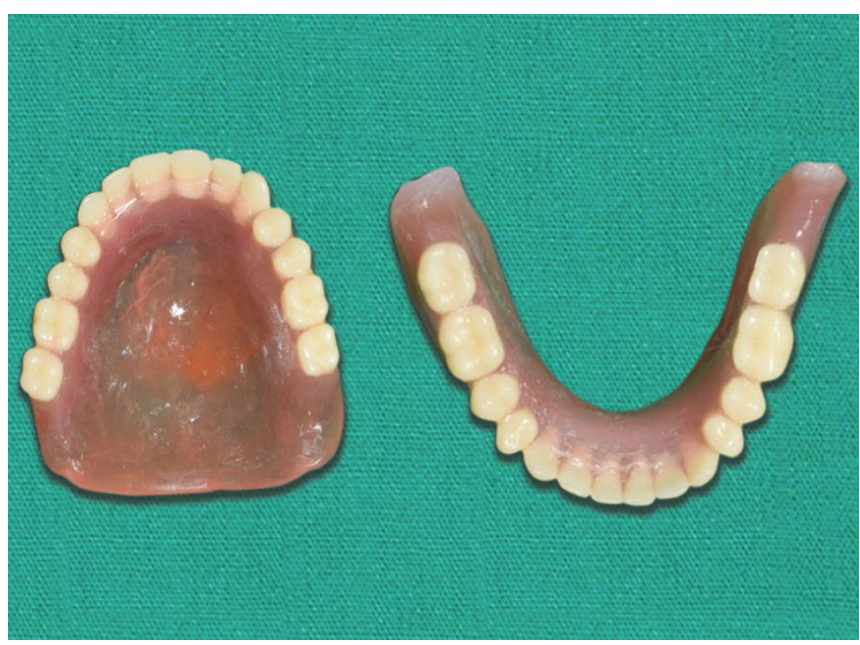

Fig. 6: Finished complete dentures
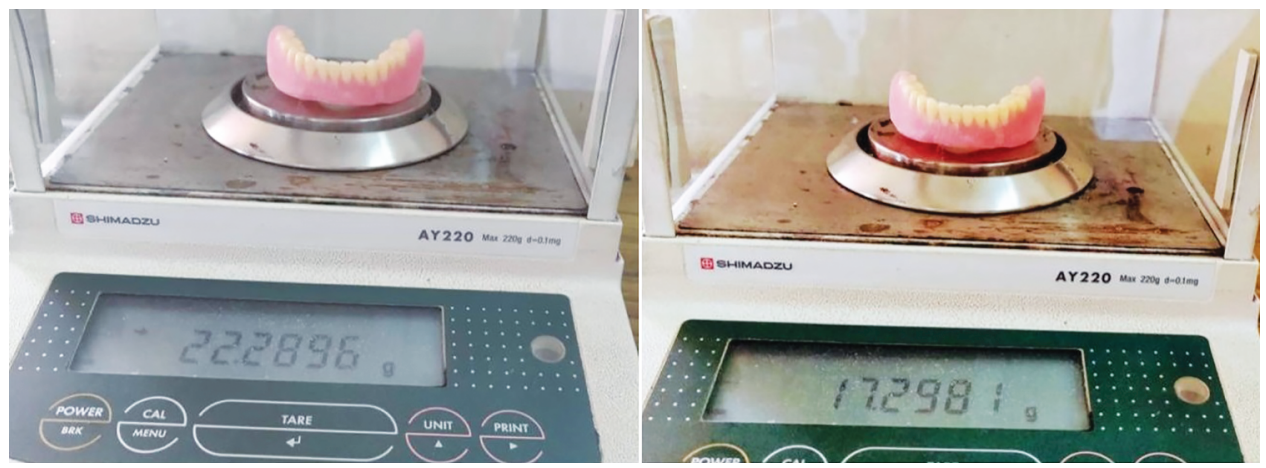

Fig. 7: Difference in the weight of the conventional and hollow mandibular complete denture

the prosthesis but also reduces the extra loads on the underlying tissues.

Various weight-reduction approaches have been tried using a solid three-dimensional spacer, including cellophane-wrapped asbestos, ${ }^{10}$ silicone putty, ${ }^{1,11}$ light-body coated gauze, ${ }^{12}$ thermocol, ${ }^{13}$ dental stone, ${ }^{14}$ play dough, ${ }^{15}$ salt $^{16}$ soap $^{17}{ }^{17}$ caramel, $^{18}$ plaster, and pumice mixture during laboratory processing to exclude the denture base material from the planned hollow cavity of the prosthesis. A major drawback of these techniques was the tedious removal of the spacer especially in the anterior region of the denture. Moreover, openings made on the distal end of the prosthesis for removal of the spacer have the potential for leakage between the heat-polymerized and autopolymerized acrylic resin portion. Alternately, fabrication of multiple and separate pieces of the prosthesis either individually or around a 3-D spacer has also been described. The individual pieces of the prosthesis are then joined using autopolymerizing acrylic resin repair techniques. ${ }^{19}$ The disadvantage of this method is that a junction is formed between the two previously polymerized portions of the denture, which may be at an increased risk of seepage of fluid into the denture cavity.

The technique described in this article uses a flexible food grade PVC tube that was incorporated in the denture. This adds to the strength of the denture and also avoids the tedious effort to remove the spacer material from the denture. Since no opening is made in the denture for spacer removal, there is no possibility of leakage into the hollow cavity. A clear template of the trial denture external contours along with a 2-mm-thick permanent denture base has been used to ensure adequate thickness of the resin all around the planned hollow cavity of the prosthesis.

\section{Conclusion}

The technique described overcomes the disadvantages of the previously described techniques. Using a flexible food grade PVC tube is a simplified technique to reduce the weight of the prosthesis without compromising its strength. The need for removal of the spacer to obtain a hollow cavity is eliminated. Hence, it is a simple, economic, and time-saving technique.

\section{Contribution Detalls}

Concept, design, and manuscript preparation were done by $\mathrm{Dr}$ Ruksana Farooqui (corresponding author). Dr Meena Ajay Aras and Dr Vidya Chitre did the manuscript editing and review.

\section{References}

1. O'Sullivan M, Hansen N, Cronin RJ, et al. The hollow maxillary complete denture: modified technique. J Prosthet Dent 2004;91(6):591-594. DOI: 10.1016/j.prosdent.2004.03.021.

2. Grunewald AH. Gold base lower dentures. J Prosthet Dent 1964;14(3):432-441. DOI: 10.1016/S0022-3913(64)80008-1.

3. Hurtado AJ. Internally weighted mandibular dentures. J Prosthet Dent 1988;60(1):122-123. DOI: 10.1016/0022-3913(88)90362-9. 
4. Wormley JH, Brunton DA. Weighted mandibular dentures. J Prosthet Dent 1974;34(1):101-102. DOI: 10.1016/0022-3913(74) 90106-1.

5. Beresin VE, Sciesser FJ. The neutral zone in complete and partial dentures. 2nd ed., St Louis: CV Mosby; 1978. pp. 15-30.

6. Ohkubo C, Hosoi T. Effect of weight change of mandibular complete dentures on chewing and stability: a pilot study. J Prosthet Dent 1999;82(6):636-642. DOI: 10.1016/S0022-3913(99)70004-1.

7. Brennon EF. Adding weight may promote retention of lower denture. Dent Surv 1973;49(3):30.

8. Nakashima K, Sato T, Hara T, et al. An experimental study on histopathological changes in the tissue covered with denture base without occlusal pressure. J Oral Rehabil 1994;21(3):263-272. DOI: 10.1111/j.1365-2842.1994.tb01142.x.

9. Jahangiri $L$, Devlin $H$, Ting $K$, et al. Current perspectives in residual ridge remodeling and its clinical implications: a review. J Prosthet Dent 1998;80(2):224-237. DOI: 10.1016/S0022-3913(98) 70116-7.

10. Worley JL, Kniejski ME. A method for controlling the thickness of hollow obturator prostheses. J Prosthet Dent 1983;50(2):227-229. DOI: 10.1016/0022-3913(83)90022-7.

11. D'souza KM, Aras MA. A simple approach to hollow maxillary complete denture fabrication: an innovative technique. J Dent Allied Sci 2017;6(2):84-87. DOI: 10.4103/jdas.jdas_23_17.
12. Caculo SP, Aras MA, Chitre V. Hollow dentures: treatment option for atrophic ridges. a clinical report. J Prosthodont 2013;22(3):217-222. DOI: 10.1111/j.1532-849X.2012.00921.x.

13. Shetty V, Gali S, Ravindran S. Light weight maxillary complete denture: a case report using a simplified technique with thermocol. J Interdiscip Dent 2011;1(1):45. DOI: 10.4103/2229-5194.77208.

14. Chalian VA, Barnett MO. A new technique for constructing a onepiece hollow obturator after partial maxillectomy. J Prosthet Dent 1972;28(4):448-453. DOI: 10.1016/0022-3913(72)90250-8.

15. Gundawar S, Zamad A, Gundawar S. Light weight dentures: an innovative technique. Contemp Clin Dent 2014;5(1):134. DOI 10.4103/0976-237X.128695.

16. Aggarwal H, Jurel SK, Singh RD, et al. Lost salt technique for severely resorbed alveolar ridges: an innovative approach. Contemp Clin Dent 2012;3(3):352. DOI: 10.4103/0976-237X.103636.

17. Qanungo A, Aras MA, Chitre V, et al. An innovative and simple technique of hollow maxillary complete denture fabrication. J Clin Diagn Res 2016;10(8):ZD23.

18. Bhushan P, Aras MA, Chitre V, et al. The hollow maxillary complete denture: a simple, precise, single-flask technique using a carame spacer. J Prosthodont 2019;28(1):e13-e17. DOI: 10.1111/jopr.12616.

19. Fattore LD, Fine L, Edmonds DC. The hollow denture: an alternative treatment for atrophic maxillae. J Prosthet Dent 1988;59(4):514-516. DOI: 10.1016/0022-3913(88)90053-4. 